\title{
JOSÉ LUIS CUERDA, LA SOCARRONERÍA MANCHEGA HECHA CINE
}

\author{
JESÚS GARCÍA RODRIGo ${ }^{1}$ \\ Real Jardín Botánico de Madrid \\ Madrid, Comunidad de Madrid, España \\ jesus.gr@rjb.csic.es
}

Cómo citar este artículo: Arroyo Serrano, S. (2020). José Luis Cuerda, la socarronería manchega hecha cine, Al-Basit (65), 259-264. http://doi. org/10.37927/al-basit.65_8

Recibido/Received: 16-02-2020

Aceptado/Accepted: $14-03-2020$

La vida del cineasta albaceteño, fallecido el pasado 4 de febrero de 2020, fue un guión basado en el humor, la ironía, lo absurdo y una notable sabiduría y, a pesar de arrancar numerosas sonrisas a los espectadores, no fue un director de comedia

Cuando Enrique Jardiel Poncela dejó escrito en su obra Máximas mínimas (1937) que «el arte de hacer reír se basa en exponerle al público, cara a cara, sus propios defectos», José Luis Cuerda no había nacido (Albacete, 1947-Madrid, 2020), pero esas palabras parecían destinadas a él. Cuerda extendió por todo el territorio nacional, a través de sus películas, un humor basado en la socarronería manchega. Nos hacía reír de situaciones surrealistas que, en realidad, eran un reflejo de algunas de nuestras actuaciones estimuladas por la miseria moral, el cinismo, la estupidez o la insolencia. La imprudencia fruto de nuestra ignorancia.

Manuel Rivas, cuyo trabajo literario Cuerda lo plasmó en La lengua de las mariposas (1999) y Todo es silencio (2012), defiende que lo mejor de los pueblos es su cosecha de humor y, ya puestos, de amor. Entrelazados, humor y amor, hacen posible una segunda vida, una historia de la risa frente a la historia amordazada por los que tienen el afán de dominar. Y así fue el humor que José Luis Cuerda reflejó en sus películas. Un humor perversamente realista y porfiadamente ideológico y sensato. Pura socarronería manchega convertida en cine.

Hace unos años Fernando Méndez-Leite, que conoció a Cuerda

\footnotetext{
${ }^{1}$ Es periodista e historiador de cine. Autor de varios libros y en la actualidad Director de Comunicación del Real Jardín Botánico-CSIC de Madrid y Jefe de su Unidad de Cultura Científica.
} 
cuando este estudiaba la carrera de Derecho y ambos, junto a José María Carreño, se veían hasta cuatro películas diarias, ya advirtió que era un director reputado por sus comedias, pero que no había llegado a la comedia como un fin, sino como una respuesta a las circunstancias externas, porque veía la vida desde la perplejidad que conduce inevitablemente al humor, a la ironía, al absurdo. El humor que quedará indeleble en sus películas tiene una finalidad. No es consecuencia de chistes fáciles ni de ocurrencias o gracietas simples, sino de estados reales, modulados, sustanciales, vertebrados. Y personales. Un humor íntimo. Una adaptación de su propia vida.

José Luis Cuerda nació en Albacete el 18 de febrero de 1947, aunque sus padres procedían de Masegoso, en plena Sierra de Alcaraz, con orígenes campesinos. Su abuelo paterno, al que todos los vecinos del pueblo le llamaban Julio, aunque su nombre era Julián, fue labrador. Y su abuelo materno, Eloy, tratante de mulas. Éste último murió antes de que Cuerda naciera, pero tuvo oportunidad de conocerlo a finales de los años noventa. De cómo fue ese encuentro, bien podría haber sido la escena de una de sus películas.

Tal y como relató en más de una ocasión el propio director, cuando fueron a enterrar a su tío Leovigildo, al hacer un hueco en el nicho, sacaron el cadáver de su abuelo Eloy y así lo conoció porque estaba incorrupto. Vestido con un traje gris, unas relucientes botas de cuero y la piel amojamada pegada a los huesos, dándole todo ello un rictus de firmeza y seriedad. Cuerda aseguraba que, a pesar del triste momento por el entierro de su tío, le hizo mucha ilusión conocer a su abuelo. Pintoresca también fue su abuela materna, Filomena, la mujer de Eloy, que, tras enviudar, vivió siempre en casa de los padres de Cuerda. Tenía asma, "fatiga, decía ella", según contaba él, y por eso siempre dormía sentada en la cama.

Su infancia transcurrió entre su primera casa en la calle Albarderos, que le vio nacer; Escolapios, donde cursó sus primeros estudios antes de pasar al instituto; y la calle María Marín, junto al parque de Albacete, su segunda y última casa en Albacete, antes de marcharse al Seminario Menor de Hellín, donde estuvo dos años, y al Seminario Mayor de Albacete, donde terminó de colgar el hábito de seminarista por dos razones. La primera es que su padre había ganado un piso en el Paseo de la Habana de Madrid jugando al póker, y toda la familia Cuerda se trasladó a la capital de España; y la segunda es que, a juicio del rector del Seminario, José María Larrauri Lafuente -que después fue obispo auxiliar de la Archidiócesis de Pamplona y obispo de Vitoria hasta su retiro en 1995-, "estaba un poco tibio en la vocación eclesiástica". De este modo, fruto del azar, nunca mejor dicho, pasó del Seminario al colegio Athenea donde coincidió con el bioquímico Mariano Barbacid. 
Aunque quien realmente influyó en José Luis Cuerda durante su juventud fue el crítico cinematográfico José María Carreño, cuatro años mayor que él. Según confesaba al escritor y miembro de la Academia de Cine Español Alberto Úbeda-Portugués, autor del libro José Luis Cuerda, ética de un corredor de fondo, a los dieciséis años únicamente leía ensayo. Leía mucha filosofía y despreciaba la novela. Pensaba que ésta solo contaba simples historietas dentro de la magna historia del pensamiento. Hasta que a los veinte años conoció a Carreño. "Él me metió en vereda”, decía, y así cambió a Jaspers, Heidegger o Sartre por Stendhal, Baroja o Galdós. Comprendió que, el "espejo sobre el camino" de Stendhal reflejaba mejor la sociedad que los libros de sociología a los que se había aficionado, o que "El árbol de la ciencia de Baroja retrababa con patetismo inigualable al hombre arrojado al mundo de los existencialismos". No obstante, siempre quedó ese poso filosófico en Cuerda como lo demostró, por ejemplo, en Amanece, que no es poco a través de Morencos, un labrador de bondad infinita que conoce al dedillo a Faulkner, interpretado por Tito Valverde.

El cine llegó más tarde. En junio del 69. Animado por Carreño se presentó al examen de la Escuela de Cine. Hizo mal el examen, y suspendió. Tozudo y pertinaz, como siempre fue, se presentó una segunda vez. Tras pasar la primera prueba, llegó la entrevista con un tribunal que componían nada menos que Jesús Fernández Santos, Miguel Picazo, José Luis Borau y Luis García Berlanga, estos tres últimos su espejo cinematográfico de aquella época. Pero, enredado con Fernández Santos en una discusión con tintes berlanguianos, para disgusto de Cuerda, tampoco aprobó. A la tercera no fue la vencida porque, con un cabreo del diez, nunca más se presentó.

Pero Cuerda fue un tipo con suerte. No ingresó en la Escuela del Cine, "y con razón", apostillaba siempre que tenía oportunidad de decirlo, pero sí lo hizo en TVE, a donde entró "por enchufe", como él mismo contaba sin rubor ni tapujos. En TVE pudo progresar aprobando una oposición como programador-adaptador y ese sueldo mensual fijo que recibía le permitió filmar varios cortometrajes. El primero fue significativo, Colgar los hábitos, que protagonizó Rosa María Mateo. Así, hasta llegar a su primera gran oportunidad, El túnel, para la serie de TVE Escrito en América, cuyo argumento estaba basado en la novela homónima de Ernesto Sábato con Mónica Randall y Gerardo Malla como protagonistas.

Esa misma suerte lo acompañó para rodar su primera película que supuso su primer trabajo con Antonio Resines. En la facultad de Derecho había conocido a Félix Tussell que, años más tarde, heredó de su padre la productora Estela Films. Un día, paseando por el Retiro de Madrid, Félix le comentó que, si escribía un guión para una comedia, 
y no era muy cara, se la produciría. Fue así como en 1981 pudo dirigir su primer trabajo para la gran pantalla, Pares y Nones. Desde entonces, todas las películas que realizó las hizo por encargo. "Tuve suerte de que esos encargos coincidieran con lo que a mí me apetecía hacer", presumía.

Después llegó una quincena de trabajos más. Algunos muy celebrados, y premiados, como El bosque animado, La lengua de las mariposas o Los girasoles ciegos. Otros que forman parte ya de la historia de nuestro cine, como Amanece, que no es poco, su película más íntima y personal rodada en Ayna, Liétor y Molinicos, tres pueblos de la Sierra del Segura a los que puso en el mapa cinematográfico. A ellos, y a un buen número de extras y actores secundarios oriundos de Albacete.

Después de varios meses de rodaje y montaje, José Luis Cuerda no pudo asistir a su estreno. Otra surrealista escena más en su vida. Fue un viernes y 13 de un soleado mes de enero de 1989 en el hoy ya desaparecido Gran Hotel de Albacete. Pero él se encontraba en su casa de Madrid, en cama, aquejado de una hepatitis por comer unas ostras en mal estado. Aún así pudo mandar un mensaje en el que decía "sin rubor creo que se trata de una película inteligente, jubilosa y una 'miaja' borde. Para mí es mi mejor película. La que tiene más cosas buenas y menos malas. Por eso quise rodarla aquí...."

No pensaron lo mismo algunos críticos albaceteños que en la prensa local lanzaron varios dardos contra el director que le dolieron, y mucho. Hoy, en cambio, hay unanimidad, dentro y fuera de Albacete, en alabar su Amanece, que... Dos días después de su muerte Juan Cruz escribía en El País, «cada escena de esa película en concreto es un verso rescatado de Dante o una frase dicha por Platón al oído de los arbustos. Miraba a los ojos de la realidad para transformarla en una metáfora de espuma o de barro. Esa película tiene su firma, como si firmara un lienzo del Bosco. Una película que era una mano pintando. La mano de Cuerda».

Y es que Cuerda se sentía albaceteño por los cuatro costados. Hasta la médula. Hasta el tuétano. Razón por la que le dolían tanto, críticas que consideraba injustas o desmedidas y por eso llevaba con orgullo y satisfacción distinciones como la de ser Miembro de Honor del Instituto de Estudios Albacetenses desde abril de 2008. Con orgullo, y una pizca de rubor de pensar en tan señalada responsabilidad porque no era una persona que le gustara levantar el cuello de más para sacar cabeza ni sobresalir por encima de nadie. Más que abundante era retenido.

Suerte también tuvo al cruzarse en su vida profesional un chico, que según un amigo, dirigía, escribía, montaba, elegía actores e, incluso, componía música. Alejandro Amenábar. El chico en cuestión estudiaba en la facultad de Ciencias de la Información de Madrid y era casi como 
él, que en sus primeros cortos, además de dirigirlos, escribía el guión, hacía de cámara y montaba la cinta. Nada más conocerlo y leer el guión de Tesis le produjo su premiada y halagada ópera prima y también las dos siguientes películas, Abre los ojos y Los otros.

El cine fue su vida, si bien por encima de él estaban tres mujeres. Su esposa María Esperanza Barcaiztegui, a quien conoció en Madrid y con la que tuvo a sus dos hijas, Irene y Elena, arquitectas ambas y alejadas, pues, de los focos y los platós de rodaje. Amaba con locura a su esposa que falleció años atrás al no superar una larga enfermedad. En una surrealista escena más de Cuerda, la enésima, dicen que en su funeral, y sin dejar de llorar, leyó el horóscopo de ese día de su mujer.

El cine fue su pasión. Bueno, en la última etapa de su vida, desde 2002, se dejó seducir por diez hectáreas en Cubilledo, en la parroquia de Gomariz, dentro del concejo de Leiro, en Ourense, en las que estableció su bodega gallega para producir un vino que supervisaba personalmente, Sanclodio, un nombre que recordaba al monasterio que dio origen al vino de Ribeiro. Curioso, porque cuando adquirió la finca apenas si sabía de vino y llevaba 20 años sin probar el alcohol por una úlcera de duodeno.

Ahora que, tras su muerte, se suceden los reconocimientos para el director, hay quien piensa que recibió pocos en vida para los muchos méritos que reunió. Sin duda, lleva razón. Y aunque Cuerda diría, sobre los premios, aquello de "ia nadie le amarga un dulce!", no se planteaba poder o no recibirlos. Estudiando el Preu, un profesor de Literatura quiso hacerle un examen sorpresa que a Cuerda no le apetecía hacer. Le preguntó: "Don Miguel, ¿qué media tengo?". "Un diez". "Pues no hago el examen". "Hombre, Cuerda no me hagas esto. Voy a tener que ponerte un 0". "Pues sale de media 5", respondió, "así que sigo aprobado". Esa era su forma de pensar y actuar. Relativizar el éxito. No necesitar el refrendo ni la consideración de nadie. No estar pendiente de una distinción por lo que hacía, pensaba o decía.

Socarrón, tozudo, inteligente, culto, afortunado..., cualquiera de estos adjetivos encajaría perfectamente en la personalidad de Cuerda, aunque si hubiera que definirlo como persona faltarían dos que, en realidad, son uno. Bueno y generoso.

Cuerda desprendía bonhomía. No solo por su aspecto que nos recordaba a ese abuelo que todo nieto hubiera querido tener o ese Papá Noel con el que todos soñamos de niños. Era una persona buena por los cuatro costados. Nada rencoroso, todo corazón. Se desprendía con facilidad de todo. Sin pedir nada a cambio.

Donó a la Filmoteca de Albacete su legado artístico. A los albaceteños nos regaló un pregón de Feria como pocos se recuerdan, y a los castellano-manchegos el discurso más divertido en un sobrio acto 
institucional, cuando en 2001 recibió en Puertollano (Ciudad Real) la Medalla de Oro de Castilla-La Mancha. Mientras algunos cobraban, y cobran, por escribir prólogos, ofrecer conferencias, presentar libros, participar en tertulias, conceder entrevistas..., él lo hizo gratis, y encantado. Más pruebas de esa generosidad, sembrar viñas en su segunda tierra, Galicia, para regalarnos vino, como recordaba Juan Cruz; dejar una vida más cómoda para regalarnos su cine; o crear una productora para regalarnos las primeras películas de Amenábar. Dicen que los hombres buenos hacen cosas, no se limitan a escribir sobre ellas. Ese era José Luis Cuerda. 